\title{
Ivermectin to reduce malaria transmission I. Pharmacokinetic and pharmacodynamic considerations regarding efficacy and safety
}

\author{
Carlos Chaccour ${ }^{1,2,3^{*}}$ (D), Felix Hammann ${ }^{4}$ and N. Regina Rabinovich ${ }^{1,5}$
}

\begin{abstract}
Ivermectin is an endectocide that has been used broadly in single dose community campaigns for the control of onchocerciasis and lymphatic filariasis for more than 30 years. There is now interest in the potential use of ivermectin regimens to reduce malaria transmission, envisaged as community-wide campaigns tailored to transmission patterns and as complement of the local vector control programme. The development of new ivermectin regimens or other novel endectocides will require integrated development of the drug in the context of traditional entomological tools and endpoints. This document examines the main pharmacokinetic and pharmacodynamic parameters of the medicine and their potential influence on its vector control efficacy and safety at population level. This information could be valuable for trial design and clinical development into regulatory and policy pathways.
\end{abstract}

Keywords: Ivermectin, Endectocide, Pharmacokinetics, Anopheles

\section{Background}

Vector control has been a fundamental pillar for the remarkable achievements in malaria control 2000-2015 [1]. Residual transmission [2, 3] and insecticide resistance [4] are some of the challenges faced for sustaining the gains of vector control. Innovation is required to reach the ambitious goals proposed by the Global Technical Strategy for Malaria 2016-2030 [5].

Ivermectin is a mixture of two semi-synthetic analogs of the fermentation products of Sterptomyces avermitilis. It belongs to the macrocyclic lactone complex; its chemical structure has been reviewed elsewhere [6]. Ivermectin is an anti-parasitic medicine approved for the treatment and control of human onchocerciasis, lymphatic filariasis (LF), strongyloidiasis [7] and scabies [8]. It is also an endectocide, a drug capable of killing arthropods that feed on a treated individual, including Anopheles

\footnotetext{
*Correspondence: carlos.chaccour@isglobal.org

1 ISGlobal, Barcelona Ctr. Int. Health Res. (CRESIB), Hospital

Clínic-Universitat de Barcelona, Barcelona, Spain

Full list of author information is available at the end of the article
}

mosquitoes. This property makes mass drug administration (MDA) with ivermectin a potential tool to reduce malaria transmission $[9,10]$. Such an intervention has the potential to reach malaria vectors that feed on the temporal and spatial gaps left by core vector control interventions (long-lasting insecticidal nets (LLINs) and indoor residual spraying (IRS).

This paper reviews the pharmacokinetic and pharmacodynamic properties of ivermectin that can affect the efficacy and safety of MDA campaigns for malaria transmission reduction.

\section{Essential pharmacology \\ Mechanism of action}

Ivermectin blocks synaptic transmission in invertebrates by binding to glutamate-gated chlorine channels in nerve and muscle, leading to hyperpolarization, paralysis and death of the invertebrate, including mosquitoes. These channels are part of the Cys-loop family of ligand-gated ion channels and ivermectin has consequently been shown to have additional effects on other members, for 
instance the gamma-aminobutyric acid (GABA), histamine, and $\mathrm{pH}$-sensitive chloride channels $[7,11]$.

In mammals, ivermectin acts as an allosteric agonist of $\mathrm{GABA}_{\mathrm{A}}$ receptor, another member of the Cys-loop family of ligand-gated ion channels. These receptors are located on neurons in many central nervous system regions (incl. the cerebral cortex, the limbic system, and thalamus) and increase chloride conductance, resulting in hyperpolarization and less formation of action potentials [12]. In vertebrates, GABA is a major inhibitory transmitter. The net effect of $\mathrm{GABA}_{\mathrm{A}}$ receptor stimulation is central nervous depression, which defines the syndrome of ivermectin toxicity in vertebrates.

\section{The glutamate-gated chlorine channel in Anopheles gambiae}

The glutamate-gated chlorine channel (GluCl) from Anopheles gambiae has recently been characterized [11]. These channels are predominantly expressed in some of the organs involved in motor and sensory systems, which explains the paralytic and other effects of the drug on mosquitoes, even at sub-lethal concentrations.

In An. gambiae, the gene for the $\mathrm{GluCl}$ can be expressed in four isoforms, but only one is insensitive to ivermectin. Little is known about the expression of these channels in wild mosquito populations. Mosquito resistance to ivermectin has not been reported, but theoretically selective over-expression of the ivermectin-insensitive isoform could develop as a resistance mechanism. However, the reduced fertility seen in mosquitoes taking sub-lethal doses of the drug $[13,14]$ could help delay this possibility.

\section{Pharmacokinetics}

The following discussion refers to pharmacokinetics of ivermectin in humans. Veterinary references are explicitly mentioned as such.

\section{Absorption}

Ivermectin is readily absorbed after oral administration. The absorption half-life ranges from 0.5 to $2.5 \mathrm{~h}[15,16]$. There are appreciable differences in systemic bioavailability (F) depending on mode of administration and disease state; ethanol based liquid formulations have up to twice the availability of solid formulations (AUC ratio 1.082.29) [15]. Infestations with worms such as Strongyloides can lead to paralytic ileus and severely impaired absorption of ivermectin. This has led to several patients requiring treatment with parenteral veterinary formulations $[17,18]$. Time since last meal does not seem to influence ivermectin's bioavailability, although this is still subject to debate $[19,20]$.

Ivermectin is subject to presystemic metabolism and efflux in the gut. Intestinal cytochrome $\mathrm{P}_{450} 3 \mathrm{~A} 4$ (CYP
3A4) can degrade ivermectin [21], and the active efflux pump P-glycoprotein (P-gp, MDR1, ABCB1), located luminally on intestinal enterocytes, transports absorbed ivermectin from the enterocyte back into the lumen [22]. Drugs or xenobiotics can induce or inhibit the activity of these mechanisms [23], as can pharmacogenetics differences, most notably in P-gp expression [24, 25].

As a lipophilic and comparatively heavy compound, ivermectin is thought to be subject to enterohepatic circulation (EHC) [16]. This is further supported by ivermectin being a substrate for important biliary efflux pumps (P-gp, and Breast cancer resistance protein (BCRP, ABCG2) [26]. Presence of EHC can increase the total exposure of a compound in that it can be absorbed multiple times, with high peak after initial administration and subsequent peaks after the compound has been excreted into bile and then reabsorbed again in the small intestine. At low doses, the peak concentration (Cmax) is proportional to the dose, but this proportionality is lost with doses equal or higher than $150 \mathrm{mcg} / \mathrm{kg}$ [27]. After a single oral dose of $150 \mathrm{mcg} / \mathrm{kg}$, the peak is around $40 \mathrm{ng} /$ $\mathrm{ml}[7,15,28]$. The reported time needed to reach Cmax (Tmax) varies but is generally accepted to be approximately $4 \mathrm{~h}$ [28].

Figure 1 represents the PK curve observed by Elkassabi [28] in Sudanese patients. The relationship between plasma concentration and the mortality of mosquitoes feeding on treated individuals is reviewed in the efficacy section below.

\section{Distribution}

Ivermectin is highly lipophilic, shows a great degree of protein binding $(>90 \%)$, and distributes widely in the body with a volume of distribution $\left(\mathrm{V}_{\mathrm{d}}\right)$ of $3.1-3.5 \mathrm{l} / \mathrm{kg}$. Owing to its lipophilicity, ivermectin partitions to adipose tissue, which increases $V_{d}$ and leads to accumulation with prolonged elimination, as drug distributes back to plasma from fatty tissue $[16,29]$. This can explain the different pharmacokinetic pattern seen in women and volunteers with higher body mass index. Protein binding becomes important in populations with high prevalence of malnutrition: there, lower plasma protein levels (especially hypoalbuminemia) will result in higher free concentrations of ivermectin and, subsequently, more drug effect and toxicity.

Distribution to the brain is hindered by the bloodbrain-barrier. Specifically, this is mediated by ivermectin's size, which is not conducive to passive diffusion, and the presence of efflux pumps, for which ivermectin is a substrate. The primary efflux pump is the P-gp (of which ivermectin is also an inhibitor), although BCRP can also transport ivermectin [22, 26]. The blood-brain-barrier therefore restricts ivermectin's access to its toxicity target 


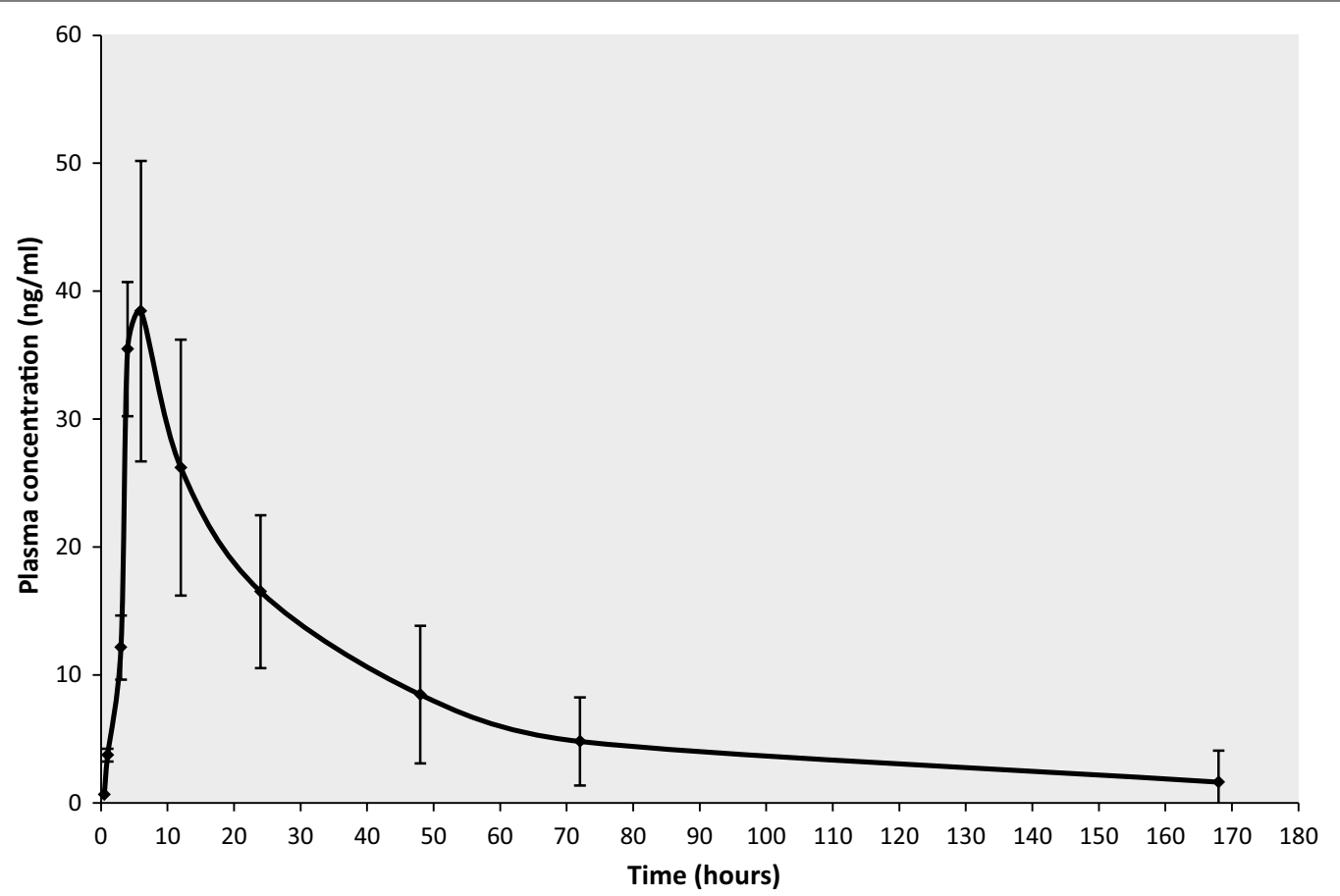

Fig. 1 The PK curve of ivermectin. Plasma concentration of ivermectin in 10 Sudanese patients infected with onchocerciasis after a single oral 150 $\mathrm{mcg} / \mathrm{kg}$ dose (Data from Elkassabi [28])

in mammals, the central nervous $\mathrm{GABA}_{\mathrm{A}}$-receptor and forms the basis for ivermectin's good tolerability. P-gp expression at birth is quite low and reaches adult levels only after 6 months. This plays a large role in the susceptibility to central nervous effects from opioids [30] and possibly also for other P-gp substrates such as ivermectin. No controlled trials of ivermectin pharmacokinetics and safety have been performed in neonates and infants. In rats, however, ivermectin significantly increased postnatal mortality, presumably through exposure from maternal milk [31].

\section{Metabolism and elimination}

The plasma half-life is approximately $18 \mathrm{~h}$ [7]. Ivermectin is metabolized by the CYP3A4 in gut and liver [32]. The hepatic cytochrome $\mathrm{P}_{450}$ system at birth has $30-50 \%$ of the activity of adults [33, 34]. By consequence, failure to adjust to weight but also for decreased hepatic clearance could theoretically lead to higher than expected ivermectin exposure and toxicity in neonates and infants. Less than $1 \%$ of ivermectin is excreted unchanged in the urine (i.e. renal insufficiency will have little impact on pharmacokinetics), with most of the drug being eliminated through bile and faeces.

Ivermectin's metabolites are present at very low concentration, which makes isolation and structural characterization challenging. Authors have resorted to first identify metabolites in vitro by means of liver microsomes before attempting an in vivo characterization [27, 35]. The correlation of both systems is good in several species tested. Following this methodology, three polar metabolites: 24-hydroxymethyl- $\mathrm{H}_{2} \mathrm{~B}_{1 \mathrm{a}}$, 24-hydroxymethyl- $\mathrm{H}_{2} \mathrm{~B}_{1 \mathrm{a}}$-Monosaccharide and 24-hydroxymethyl$\mathrm{H}_{2} \mathrm{~B}_{1 \mathrm{~b}}$ account for up to $50 \%$ of all metabolites in liver tissue of cattle, rat and sheep in the first 14 days after dosing $[27,35]$. In swine, more than two-thirds of liver residues are composed of $3^{\prime \prime}-O$-desmethyl $-\mathrm{H}_{2} \mathrm{~B}_{1 \mathrm{a}}$ and $3^{\prime \prime}$-O-desmethyl- $\mathrm{H}_{2} \mathrm{~B}_{1 \mathrm{~b}}[27,35]$.

In humans, studies with radio-labelled ivermectin show that peak plasma concentration of metabolites is about twice that of the parent drug and occurs later, at $7 \mathrm{~h}$ (vs four for parent drug) [36]. Plasma metabolites are less polar than the parent drug and could be fatty acid ester conjugates of the monosaccharides or aglycone of the parent drug [36]. The major metabolites excreted are $3^{\prime \prime}-\mathrm{O}$-desmethyl- $\mathrm{H}_{2} \mathrm{~B}_{1 \mathrm{a}}$ and $3^{\prime \prime}-\mathrm{O}$-desmethyl- $\mathrm{H}_{2} \mathrm{~B}_{1 \mathrm{a}}$ Monosaccharide in urine and faeces respectively [36]. The plasma half-life of metabolites is about $72 \mathrm{~h}$, fourfold that of the parent drug. If these metabolites have mosquitocidal activity, this could explain recent findings of a "post-ivermectin" effect in which mosquitoes feeding on treated volunteers long after the parent drug is no more identifiable in plasma still show an increased mortality $[37,38]$. 
Ivermectin is metabolized by CYP3A4 [32] but in vitro studies suggest it does not significantly inhibit its metabolizing activity or that of CYP2D6, CYP2C9, CYP1A2, and CYP2E1, all involved in its metabolism to a lower extent [7]. There is, however, a theoretical possibility of interaction with CYP3A4 inhibitors (such as protease inhibitors) or inducers such as rifampicin.

Ivermectin is both a substrate and a potent inducer of the P-gp. P-gp plays a role in the transportation of ivermectin to the intestinal lumen and in preventing its crossing of the blood-brain barrier [39]. P-gp inhibitors (such as antifungal azoles) can increase ivermectin plasma levels in animals [40, 41]. Post-marketing reports of increased International Normalized Ratio (INR) have been rarely reported when ivermectin was co-administered with warfarin [7].

The drug-drug interactions of ivermectin with artemisinin-based combination therapy (ACT) have not been well explored. Co-administration with artemetherlumefantrine was well tolerated in a small study in Burkina Faso [42], data on its safety in combination with dihydroartemisinin-piperaquine will be available from 141 participants in the IVERMAL trial [43] and further evidence on its safety in combination with dihydroartemisinin-piperaquine and primaquine will be available from the IMSEA trial [37].

\section{Assessing the efficacy of ivermectin to kill mosquitoes}

Efficacy is defined as the killing effect of ingestion of ivermectin by mosquitoes via blood (either through a direct-skin blood meal or through in vitro/membrane feeding methods). The evidence supporting this lethal effect has been reviewed extensively $[9,10,44]$ and will not be re-visited here (see Additional file 1 for all studies). However, studies to assess the efficacy of ivermectin in reducing the survival of mosquitoes are not standardized. A typical approach is to allow a sample of vectors to feed on blood containing the drug or on a treated subject. Resulting mortality is assessed at intervals and reported in different formats.

\section{The concept of lethal concentration $\mathbf{5 0}\left(\mathrm{LC}_{50}\right)$}

The $\mathrm{LC}_{50}$ is a commonly seen metric of ivermectin killing effect on mosquitoes $[45,46]$; it is the concentration of ivermectin in the imbibed solution or blood meal that kills $50 \%$ of the mosquitoes during a defined period of observation. It is a measure of efficacy similar to the minimum inhibitory concentration used in bacteriology and it should not be misconstrued that the goal is to kill only $50 \%$ of the feeding mosquitoes. The $\mathrm{LC}_{50}$ will vary according to the time point chosen for the mortality assessment. At a given drug concentration and mosquito species, the 3-day $\mathrm{LC}_{50}$ will be higher than the 9-day $\mathrm{LC}_{50}$, i.e. less drug is needed to kill $50 \%$ of the mosquitoes in 9 days, due to the addition of naturally occurring deaths. An alternative approach would be to determine the time to median mortality at any given concentration, but this has not been commonly used.

The feeding method used to determine the $\mathrm{LC}_{50}$ could also influence the measurement outcome. Ivermectin is highly lipophilic, it is found in higher concentrations in dermal and adipose tissue than venous plasma [29]. It is hypothesized that the resulting concentration gradient between the adipose tissue and the capillary blood may increase the drug concentration in the capillaries when compared to venous blood. This may be relevant as mosquitoes imbibe blood from subdermal capillaries and thus may ingest higher concentrations of ivermectin than would be predicted from the drug concentration in venous samples, i.e. mosquitoes feeding directly on the skin of a volunteer may have higher mortality than mosquitoes feeding on the blood of the same volunteer in a membrane-feeding device. Evidence is being generated with aim to clarify confounding of mortality measures by route of administration to mosquitoes, and perhaps other factors.

\section{Pharmacokinetic considerations regarding efficacy}

The efficacy of ivermectin to reduce transmission is expected to be a function mainly of its lethality to the vector population. Additional benefit will be obtained from a change in the age structure of the mosquito population: in areas of ivermectin MDA, there is increasing mortality of older biting females, this skews the mosquito population towards younger (less infectious) ages and reduces transmission beyond the initially seen lethality for up to 3 weeks $[10,47]$. Additionally, older mosquitoes seem to be more susceptible to ivermectin that their younger counterparts [48].

Along these lines, the sublethal effects of the drug on mosquito fertility and flying capacity [13, 14, 45] will contribute to the overall effect (see "Other effects of ivermectin" below). Both lethality and sublethal effects will be closely related to drug concentration in reached in the blood of treated individuals and to the time this blood concentration is sustained.

All the concepts defined here refer to the mortality of mosquitoes feeding on a single treated person.

\section{The mortality of mosquitoes caused by ivermectin has a dose-response gradient and is limited by the theoretical $L C_{100}$}

The higher the concentration, the higher the mortality of mosquitoes feeding on those individuals at that time will be [42], this finding has been supported by modelling [49]. This increase in lethality will be limited by the 
theoretical $\mathrm{LC}_{100}$ (the concentration killing $100 \%$ of biting mosquitoes, this is a theoretical concentration difficult to reach in nature). Any blood concentration above this threshold will not contribute to additional mortality (one cannot kill more than $100 \%$ of the biting mosquitoes). Figure 2 illustrates this concept.

\section{Ivermectin's impact on mosquito mortality is directly related to the time there is a lethal concentration in the blood}

The longer the drug remains in the blood, the more mosquitoes it will kill or disable. Any increase in duration of

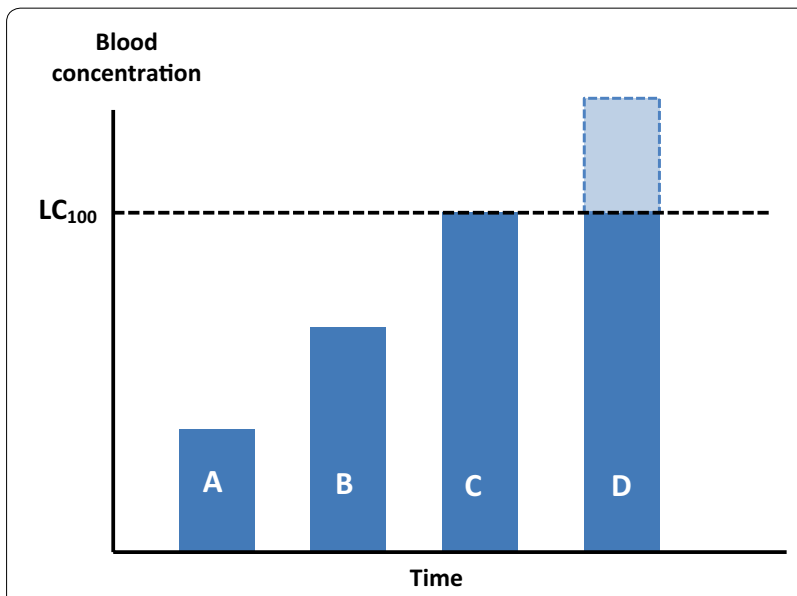

Fig. 2 The effect of increasing concentrations of ivermectin on its efficacy. Columns $A, B$ and $C$ are expected to have increasing efficacy. The area above the $L C_{100}$ in column $D$ will not contribute to further mosquito mortality. In the absence of a long elimination tail, the efficacy of the dose of column C and that of column D will be equal. Columns are used for illustration. $\mathrm{LC}_{100}$ : lethal concentration 100 mosquitocidal concentrations is expected to contribute to additional mortality. Modelling shows that the time the drug remains in blood above mosquito-killing levels is the parameter that drives impact on transmission [50].

\section{The lethal effect is heterogenic}

The lethality observed in any mosquito population feeding on a treated individual after a single oral dose will not be uniform. It will vary according to the plasma levels at the time of biting in close relationship with the PK of the drug. Figure 3 illustrates this concept. The total effect will be the sum of the proportions dying at different time points.

\section{The lethal effect could be a function of the area under the curve}

The blood concentration and the time the drug remains in the blood can be represented by the area under the curve (AUC). Because the blood concentration above the theoretical $\mathrm{LC}_{100}$ cannot add to lethality, the efficacy can be expected to be a function of the AUC that is below the $\mathrm{LC}_{100}$. The AUC below $\mathrm{LC}_{100}$ will vary according to the magnitude of the single dose given, the number of doses, the administration route, the absorption and distribution rates of the drug as well as its metabolism and elimination. Secondary release from adipose tissue after accumulation could also play a role.

\section{Conceptually, the ideal ivermectin dose would maximize the} time drug level is near the LC100 without wasting drug going beyond the level at which most mosquitoes are killed

Given the heterogeneity of mosquito lethality in time, in the (theoretical) presence of a constant biting rate, a "peaked"

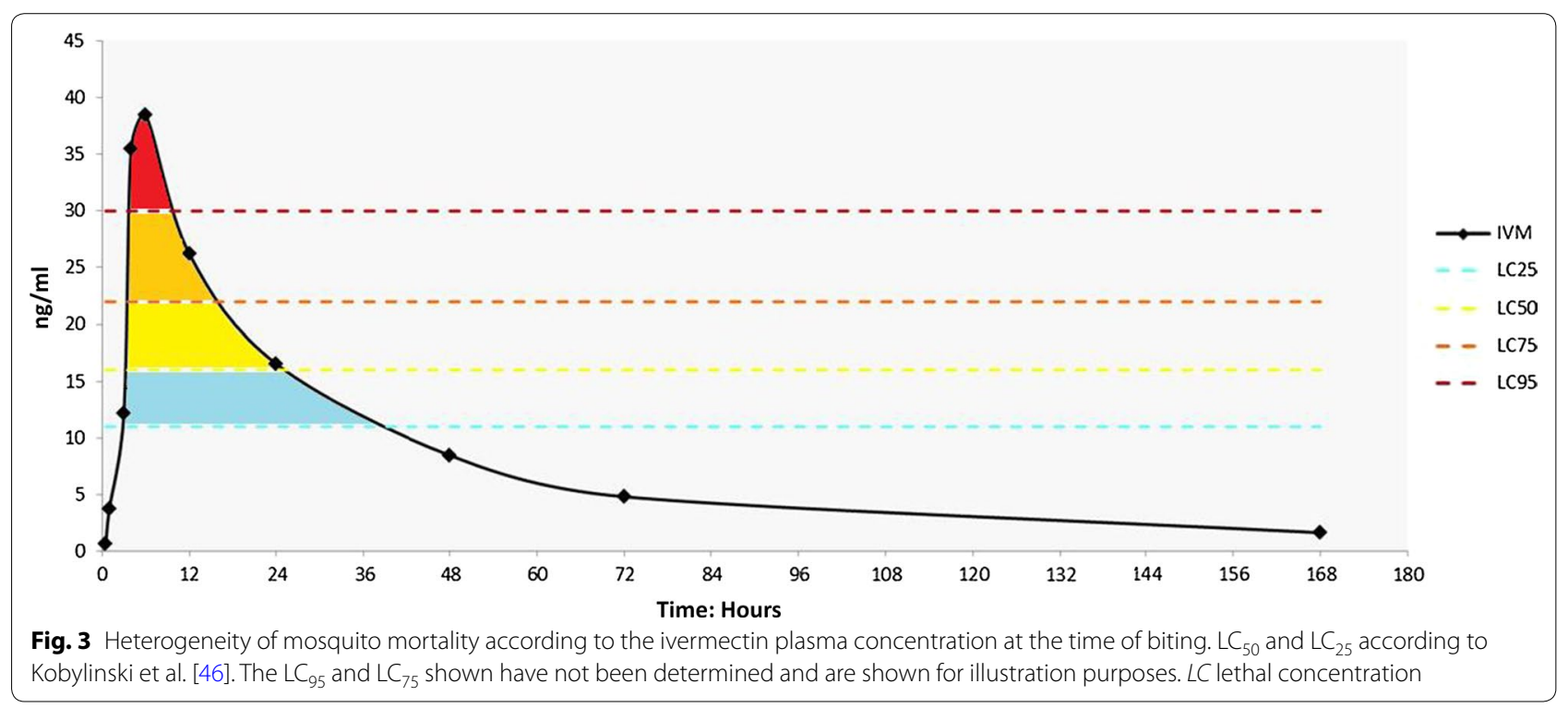


curve with a Cmax close to the LC100, but with a narrow base, can have the same efficacy of a wider curve, even if the Cmax is lower. Figure 4a illustrates this concept. Ivermectin MDA could be however tailored to make the Cmax coincide with the peak biting activity of the local vectors [11].

Following this rationale and considering the point illustrated in Fig. 2, a large dose yielding a "peaked" curve with $\mathrm{Cmax}$ high above the $\mathrm{LC}_{100}$ could be less efficacious than a dosing scheme yielding the same area under the curve without surpassing the $\mathrm{LC}_{100}$. This is because the AUC above the $\mathrm{LC}_{100}$ will not directly contribute to the efficacy. This is illustrated in Fig. $4 \mathrm{~b}$.

\section{Time above lethality target}

Modelling can help generate a robust hypothesis on the mosquito lethality target at a population level. This will

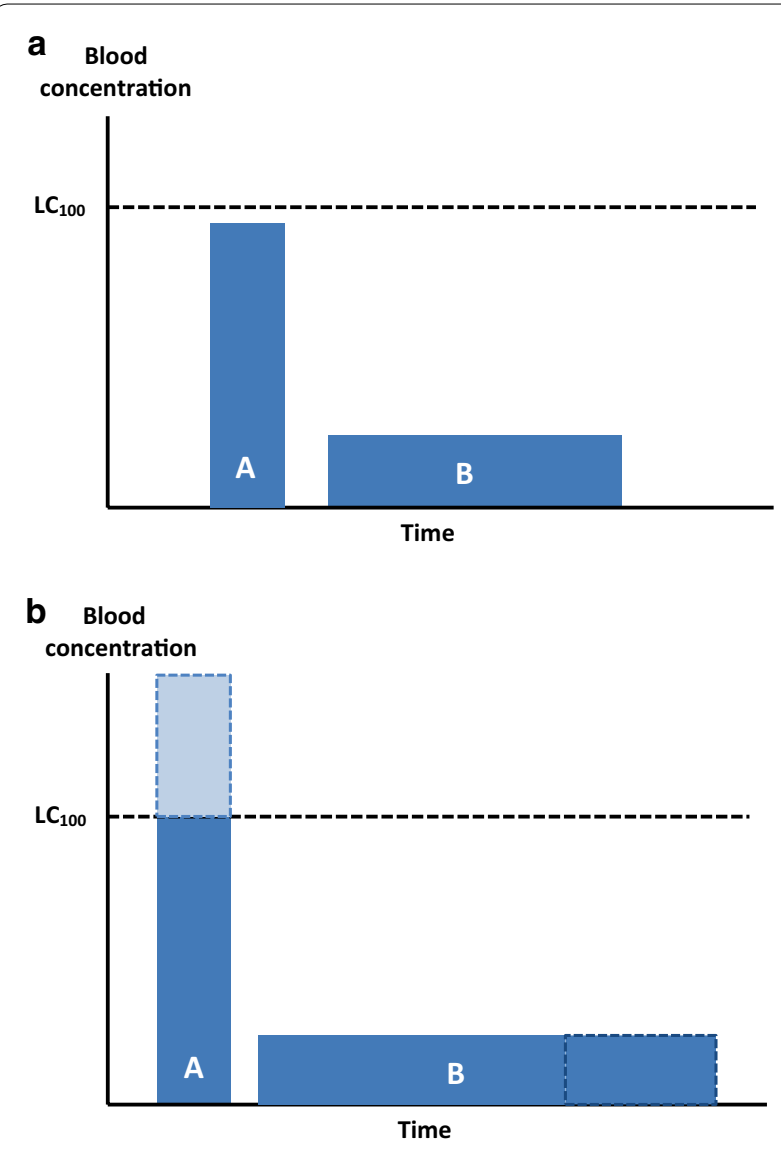

Fig. 4 AUC of different dosing schemes and their potential relationship with efficacy. $\mathbf{a}$ The area of both columns is the same $(A=B)$, hence, in the presence of constant biting rate, the total number of mosquitoes killed by $A$ and $B$ might me similar, even if $B$ does not reach the same Cmax. $\mathbf{b}$ If the theoretical LC $_{100}$ is surpassed (light blue area), the drug consumed to reach such plasma levels is partly wasted because it does not contribute to efficacy and may in turn increase the possibility of side effects. Columns are used only for illustration. $L C_{100}$ lethal concentration 100 be a function of the individual dose per body weight. The time above lethality target is related to the area under the curve but takes into consideration the susceptibility of the local mosquitoes. It can be expressed in time as a "mosquitocidal window". Figure 5 illustrates how the susceptibility of the local vector can influence this variable.

\section{Dose-response curves}

The slope of the curve will represent the logarithmic increase in the AUC below $\mathrm{LC}_{100}$ needed to kill a higher proportion of mosquitoes. Although recent data suggests the relationship between plasma concentration and mosquito mortality is linear at the individual level [42], at the population level the relationship AUC-efficacy is unlikely to be so. Figure 6 illustrates this concept.

\section{Options to increase the efficacy of ivermectin}

Higher doses per body weight, multiple dose regimens, or slow-release formulations are all theoretical ways to increase the AUC and hence the efficacy. The duration of sublethal concentrations can play an important role in general efficacy as vectors imbibing sublethal concentrations can have a higher mortality rate due to impaired motility or temporary paralysis (knock-down). Epidemiological and PK modelling can be used to plan the doses and regimens to be tested in field trials, but care must be taken to reflect the potential importance of this additional effects.

\section{Higher doses (increasing the Cmax)}

Using higher doses per body weight will result in larger AUC driven by a higher Cmax (Fig. 7). This will result in longer time above lethal concentrations because the slope of elimination will remain the same. This is the most straight-forward method because it could be implemented using the current oral formulation at a single encounter. The main challenges with this approach include the safety of a higher Cmax that could increase toxicity while and partial drug waste due to a portion of the AUC above the theoretical $\mathrm{LC}_{100}$. Acceptability in areas where previous lower ivermectin doses have been used must be part of integrated community engagement, also needed for the understanding of direct and indirect benefits that can be expected from this approach.

\section{Multi-dose regimens}

A multiple-dose regimen would result in a series of peak concentrations that could have cumulative effect depending on the frequency of the doses (Fig. 8). The effect of every dose would also be limited by the theoretical $\mathrm{LC}_{100}$ plateau. The main limitations of this approach are compliance and the logistics of multiple rounds of MDA. Additionally, the valleys caused by the intermittent dosing may result in "vulnerable windows" because levels 

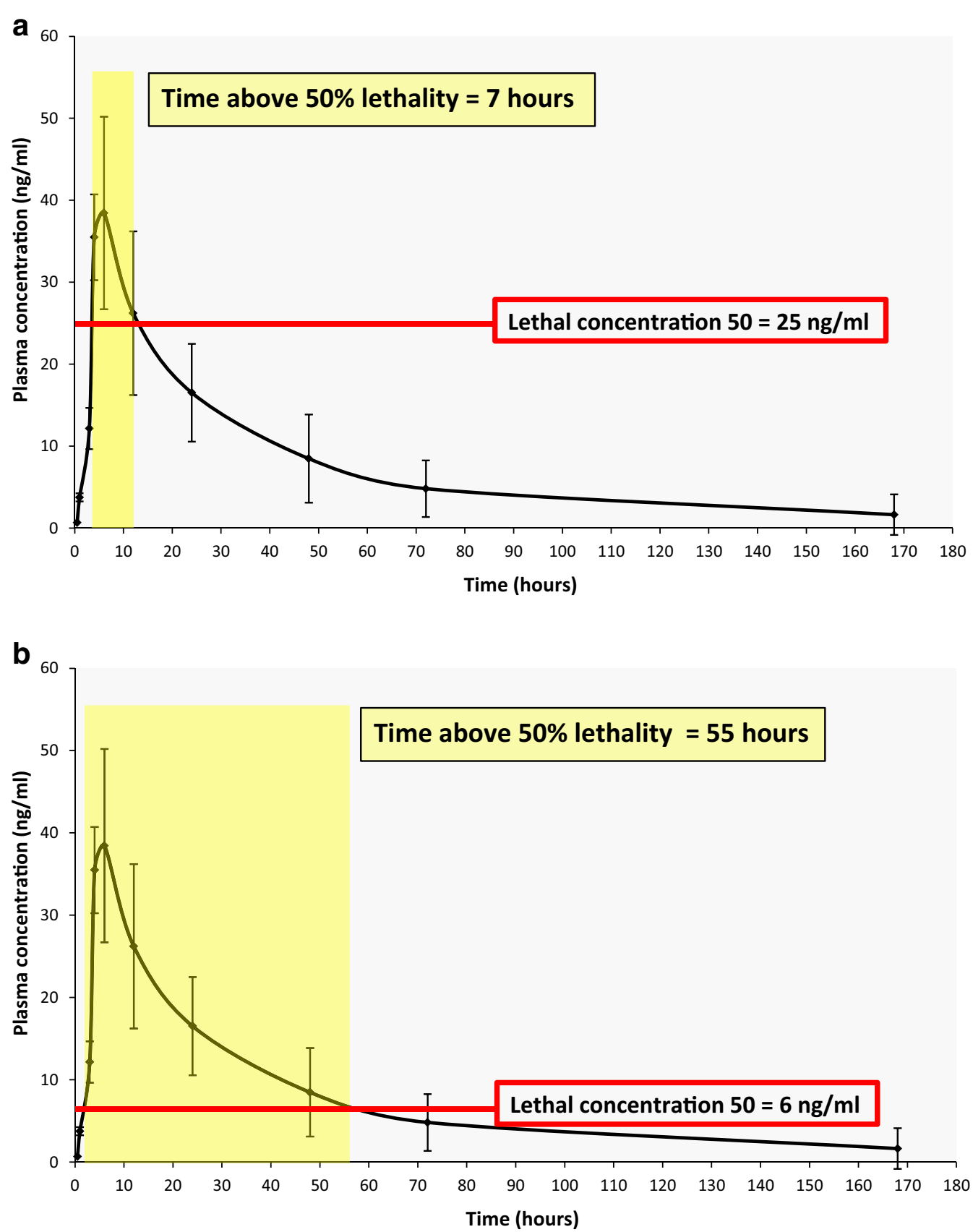

Fig. 5 The time above lethality and the "mosquitocidal window". An illustration of how the lethality target selected and the susceptibility of the local vectors can affect the efficacy of ivermectin to reduce malaria transmission. The curves represent the PK of ivermectin after a single oral 150 $\mathrm{mcg} / \mathrm{kg}$ dose according to Elkassaby [28]. In both panels, the lethality target is the $\mathrm{LC}_{50}$. The vectors of $\mathbf{a}$ are less susceptible and higher concentrations are required to kill $50 \%$ of them, the time above lethality target is $7 \mathrm{~h}$. The vectors of $\mathbf{b}$ are much more susceptible, this increases the time above lethality eightfold. LC lethal concentration

might be in the insufficient dose range, decreasing efficacy. Preliminary data from a recent cluster-randomized trial showed a $20 \%$ reduction in clinical incidence of malaria in children under five by active case detection in areas where a $200 \mathrm{mcg} / \mathrm{kg}$ dose was given to all eligible population every 3 weeks for six doses [51].

\section{Slow-release formulations}

A long-lasting, slow-release formulation [52, 53] would have effect on the Cmax depending on the release rate, which, if controlled, could theoretically improve the efficacy/safety ratio (Fig. 9). The main issue with this approach is investment in R\&D and the need to reassess 


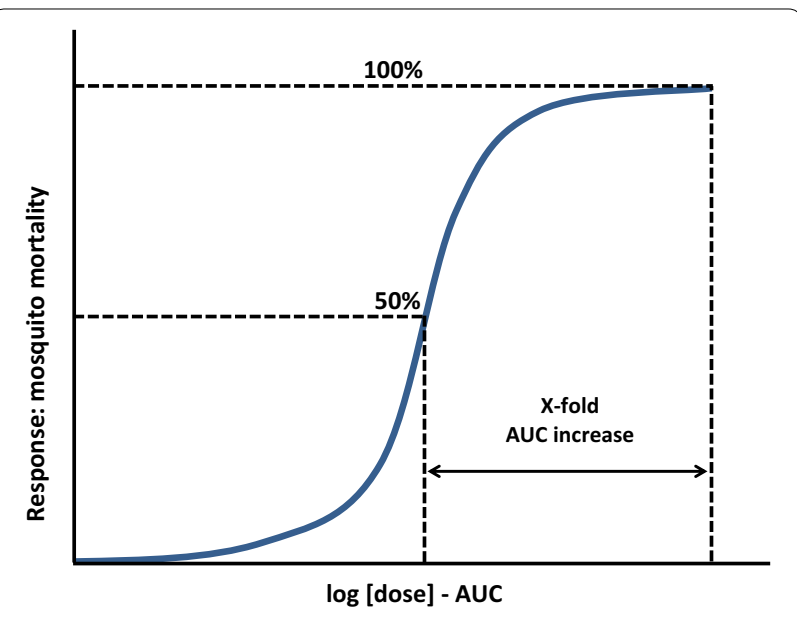

Fig. 6 Logarithmic ivermectin dose-response curve as mosquitocidal. In the case of ivermectin, the dose will be a function of the AUC and the response a function of the total mosquito mortality plus the sublethal effects. AUC area under the curve

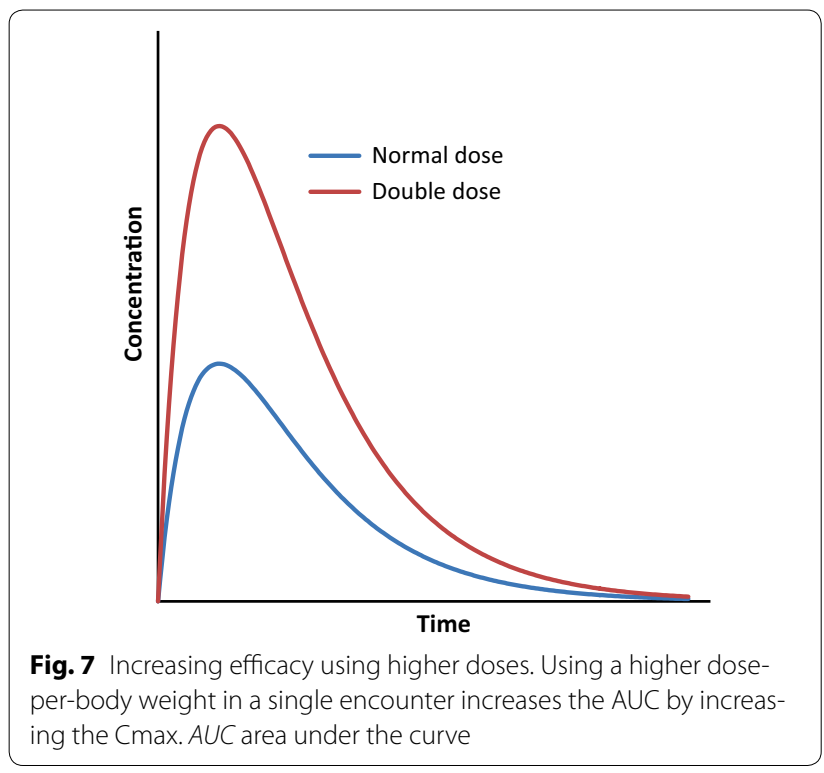

the efficacy of the new formulation on the treatment of neglected tropical diseases.

\section{Other options}

One alternative to increase the AUC is to prolong the half-life of the drug (alter the elimination slope), which could theoretically be achieved with CYP3A4 and/or P-gp inhibitors. Doing so, however, may unreasonably increase the risk of toxicities and drug interactions, especially with antiretrovirals. The addition of a rather specific CYP3A4 inhibitor with no P-gp inhibition, such as voriconazole [54], would be an interesting approach as this would increase bioavailability of ivermectin while not impairing P-gp's vital function at the blood-brain barrier.

\section{Other effects of ivermectin}

In addition to the direct killing effect of ivermectin, there several sub-lethal effects that can increase the net impact of the drug on malaria transmission:

\section{Effect on vector fertility}

Several studies report diminished fertility of Anopheles mosquitoes after an ivermectin-loaded blood meal containing sub-lethal concentrations $[13,14]$. Reduced hatching of the laid eggs has also been observed. Of note, this effect may delay but not completely avoid the appearance of ivermectin-resistant mosquitoes.

\section{Effects on vector behaviour}

Knock down, lesser flight performance and reduced tendency to bite have all been reported after taking sublethal ivermectin concentrations in a blood meal $[45,55]$. These effects measured in the laboratory might contribute to greater mosquito mortality in the field.

\section{Effects on the parasite}

In the mosquito, ivermectin might inhibit plasmodium sporogony $[46,56]$ and could have an effect on liver schizonts as seen in vitro $[57,58]$ and confirmed in mouse model [57], these findings require further evaluation.

\section{Key knowledge gaps regarding efficacy Methods}

- Lack of standardized protocols for the assessment of ivermectin's efficacy.

- Lack of correlation between the mortality observed in mosquitoes taking ivermectin through membrane vs those taking it via skin-feeding. Validating membrane feeds as a reliable, predictive assay compared to direct skin-feeding would facilitate evaluation of different approaches.

$L c_{50}$

The main gap is dearth of data on The $\mathrm{LC}_{50}$ determined via human direct skin-feeding. Results should be obtained for different species and strains in different sites, especially for known outdoor-biting species or main vectors of areas targeted for elimination.

\section{Time above lethality}

Determine the blood concentration that should be achieved with an ivermectin-based tool and how long should it be sustained in order to have a measurable impact on transmission. 


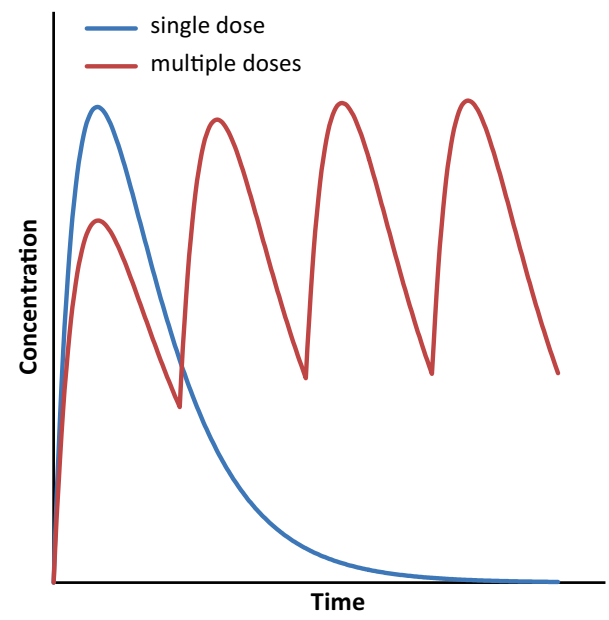

Fig. 8 Increasing efficacy by means of multiple dosing. Using a series of multiple doses can increase the AUC while avoiding reaching plasma concentrations where the efficacy/safety ratio is lower

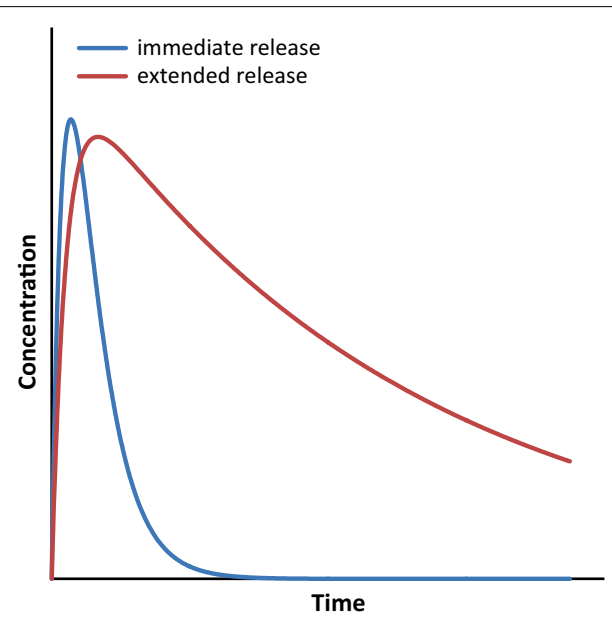

Fig. 9 Increasing efficacy with a slow-release formulation. A long lasting formulation would increase AUC by prolonging time above lethality, without significant increase in the Cmax and theoretically improving the efficacy/safety ratio. AUC area under the curve

\section{Other effects}

Assess whether ivermectin, by having a mechanism of action different from all public health insecticides available today, could help reduce the risk of insecticide resistance that is not CYP-mediated. Also the influence of ivermectin's effects on mosquito fertility in potentially delaying the appearance of ivermectin-resistant mosquitoes.

\section{PK considerations regarding safety}

Ivermectin has been licensed for human use for almost 30 years, and its safety has been assessed in over 70 trials. More than 2.7 billion $150-200 \mathrm{mcg} / \mathrm{kg}$ single doses have been distributed by the Mectizan Donation programme [59]. Since community use of ivermectin implies that drug will be given to at risk and infected individuals, all for indirect benefit of lowering malaria disease rates, the safety profile and the risk-benefit assessment will be critical. For use as a vector control measure, it is the combination of the blood levels and the duration of these levels that will need to have an acceptable safety profile. Both parameters are directly related to drug dosage and regimen required to reach impact. Regarding safety, the adverse effect rate is also expected to be a function of the cumulative dose. Host factors such as illnesses and co-administered drugs must also be taken into account.

\section{Therapeutic index}

Drugs developed for elimination endeavours and MDA administration must have a high therapeutic index [60]. The therapeutic index is a measure of the range of doses that elicit a therapeutic response without unacceptable adverse effects [61]. Using ivermectin for vector control, this relationship will be between the mosquito mortality (as a proxy for efficacy) and the AUC (as a proxy for dose per body weight and number of doses). Figure 10 illustrates this concept.

As an example, Guzzo et al. administered 1.404-2.000 $\mathrm{mcg} / \mathrm{kg}$ in a single dose to 16 healthy volunteers in the US (>tenfold the usual $150-200 \mathrm{mcg} / \mathrm{kg}$ single dose for onchocerciasis) and did not report a greater adverse effect rate than in controls [62]. These findings suggest the therapeutic index of ivermectin for onchocerciasis control is at least higher than 10. For malaria control the therapeutic index will be lower as the dose needed will be higher. The findings of Guzzo et al. provide a good safety reference at $3.200 \mathrm{mcg} / \mathrm{kg}$ in a week (see Table 1). The Centers for Disease Control and Prevention recommends doses of up to $1.400 \mathrm{mcg} / \mathrm{kg}$ within a month for the treatment of severe crusted scabies [63].

\section{The efficacy/safety ratio}

A particular AUC will elicit a specific efficacy/adverse effects ratio. This ratio is expected to increase exponentially with the AUC; in theory, once the $\mathrm{LC}_{100}$ has been reached, this ratio can only increase at the expense of the time above lethality. Using the therapeutic index concept described above, after a certain cumulative dose, toxicity will start to increase and the efficacy/adverse effects ratio will be reduced (Fig. 11). Increasing the dose per body weight given in a single encounter is a possible strategy to increase the efficacy. This strategy, however, must be carefully evaluated since the AUC above the $\mathrm{LC}_{100}$ will minimally contribute to efficacy and may in turn increase the risk of toxicity. 


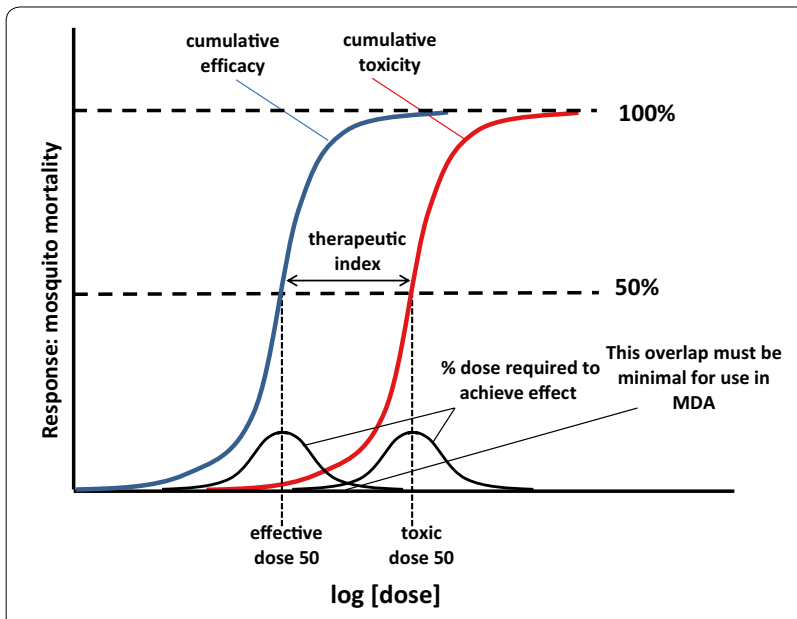

Fig. 10 Therapeutic index. AUC area under the curve, MDA mass drug administration (Adapted from Golan et al. [61])

\section{Safety profile of ivermectin in community campaigns-} implications for malaria

Since the creation of the Mectizan Donation Programme in 1988, more than 2.7 billion doses of ivermectin have been distributed for the control of onchocerciasis and lymphatic filariasis in Africa, Latin America, and Asia [59]. Exclusion criteria are: children under $15 \mathrm{~kg}$, pregnant women, nursing mothers in the 1st week after delivery, the severely ill and those with known hypersensitivity to the drug [64]. Coverage target is normally between 65 and $80 \%$ of the whole population [65].

\section{Safety of ivermectin in onchocerciasis MDA campaigns}

In onchocerciasis-infected patients, adverse events (AE) to ivermectin are usually mild, transient, associated with intensity of microfilarial infection and primarily characterized as mild Mazzoti-type reactions to dying microfilaria [66]. These effects wane in subsequent administrations [67]. No significant association has been found between ivermectin plasma levels and $\mathrm{AE}$ recorded [68]. A recent Cochrane review of ivermectin for river blindness shows that side effects are rarely reported [69]. Outside Loa loa endemic areas (see below), the drug is remarkably safe.

\section{Loa-associated encephalopathy}

Loa loa is a parasitic infection that is broadly present in geographies overlapping the onchocerciasis/LF programmes. While causing limited direct disease, administration of ivermectin to individuals infested with Loa loa can result in encephalopathy in $0.01-0.11 \%$ of the treated population [70], if the Loa loa burden is high $(>30.000$ parasites $/ \mathrm{ml}$ ), the odds ratio can be above 1000 [70]. The syndrome includes confusion, lethargy and coma.
The pathophysiology behind this syndrome is not clear, but rapid killing of Loa microfilariae or even defects in transmembrane efflux pumps may play a role [70, 71]. At a population level, high levels of microfilaraemia are seen in $1 \%$ of the population in areas with an overall Loa loa prevalence greater than $20 \%$. This threshold was used by the Mectizan Expert Committee and the Technical Consultative Committee to define the preventive strategies recommended for ivermectin distribution in Onchocerca and Loa co-endemic areas [72]. Nonetheless, the risk of this severe adverse event excludes parts of Loaendemic central Africa from ivermectin MDA campaigns for the elimination of onchocerciasis; this includes areas of Angola, Cameroon, Central African Republic, Chad, Congo, Democratic Republic of the Congo, Equatorial Guinea, Ethiopia, Gabon, Nigeria and South Sudan [73].

Several tools and strategies are emerging in response to the limitations caused by Loa which creates a near term window of opportunity for malaria: New diagnostic tools (loascope) allow for quantitative population screening in real time [74] and novel biomarkers could also predict burden at individual level [75]. This test and (not) treat strategy may offer a programmatic approach to addressing the Loa barrier to ivermectin treatment. This strategy could reduce the Loa burden at population level, lowering the risk of parasite-burden-related adverse reactions. Finally, single-administration of drug combos [76] can offer a rapid pathway to LF elimination, this treatment also reduces Loa loa burden and thus risks from ivermectin for any indication (including malaria).

\section{Safety of ivermectin at doses higher or more frequent than approved for NTDs}

A single ivermectin dose of $150-200 \mathrm{mcg} / \mathrm{kg}$ results in a too short-lasting mosquito-killing effect to be applicable for malaria impact. Therefore, for this indication, higher doses and/or multi-dose regimens than those currently used for onchocerciasis will be needed. A range of dosages are already recommended for different indications. The FDA-approved ivermectin dose for strongyloidiasis MDA is $150 \mathrm{mcg} / \mathrm{kg}$ (every 12 months), although the possibility of quarterly use in individual patients is also included in the label [7]. The French authorities recommend up to $400 \mathrm{mcg} / \mathrm{kg}$ for the control of lymphatic filariasis in selected areas [77]. For severe crusted scabies, up to seven $200 \mathrm{mcg} / \mathrm{kg}$ doses within a month in combination with topical treatment and keratolytics are recommended in the US [63] and Australia [78]. The possibility of using more than 3 doses for the treatment of moderate to severe crusted scabies cases is included in the Australian label [8].

Very few studies, at varying doses and frequencies, have evaluated the safety of ivermectin regimens at doses 


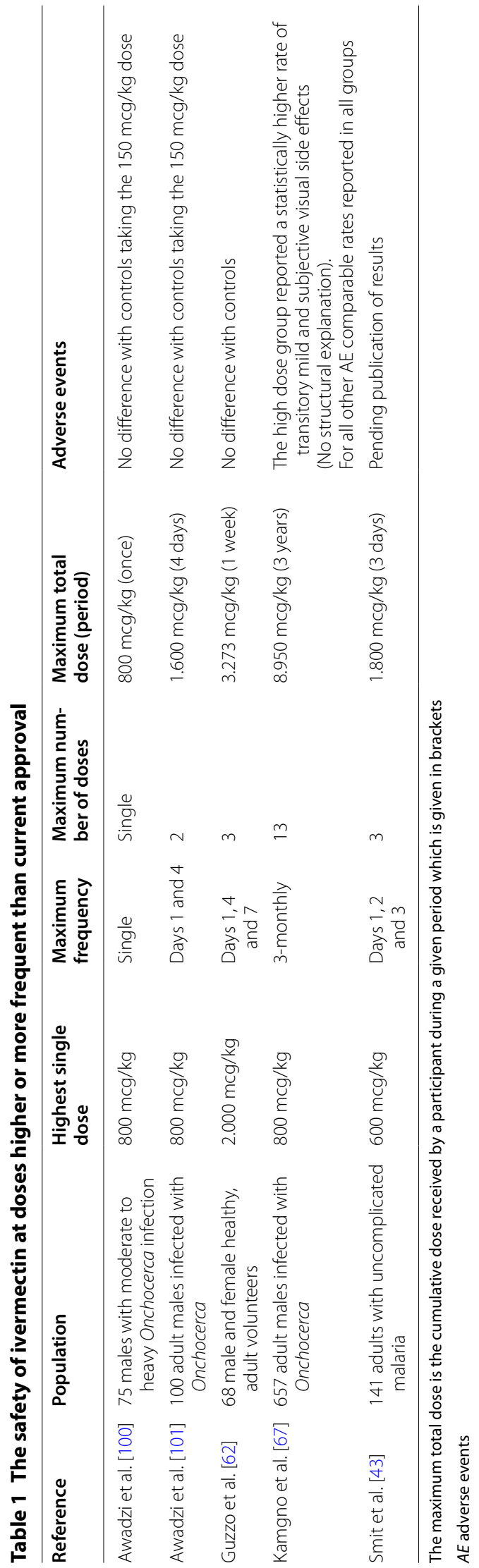




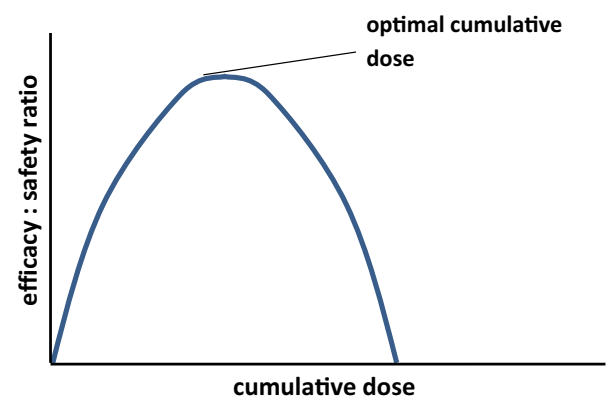

Fig. 11 The efficacy/safety ratio. The relationship between the efficacy: adverse effect ratio and the cumulative dose

above $400 \mathrm{mcg} / \mathrm{kg}$ for control of NTDs (Table 1). Pharmacokinetic modelling suggests that a regime consisting of a daily dose of $600 \mathrm{mcg} / \mathrm{kg}$ for 3 days has the potential to sustain ivermectin concentrations lethal to Anopheles mosquitoes for at least 1 week [43]. This is the basis of the recently finished IVERMAL trial in Kenya [43].

The skewing of the age structure of the mosquito population for around 3 weeks after a single round of MDA for onchocerciasis $(150 \mathrm{mcg} / \mathrm{kg})$ could also support reduction in transmission of malaria. This has been used as the basis for the RIMDAMAL trial [79] which consisted on six rounds of ivermectin MDA 3 weeks apart each. Preliminary data from this cluster-randomized trial shows no significant adverse events with this those [51].

\section{Safety of ivermectin during pregnancy and lactation}

Pre-clinical studies in pregnant mice, rats and rabbits show teratogenicity at doses toxic to the mother (400 $\mathrm{mcg} / \mathrm{kg}, 5.000 \mathrm{mcg} / \mathrm{kg}$ and $3.000 \mathrm{mcg} / \mathrm{kg}$ during pregnancy days 6-18 respectively) [7, 80]. Ivermectin can produce delayed development and increase pup mortality in rats at maternal doses of $1600 \mathrm{mcg} / \mathrm{kg}$ [80]. It is estimated that in Onchocerca-endemic areas, up to $50 \%$ of pregnant women in the first trimester are systematically inadvertently treated with ivermectin during MDA campaigns [81].

Five studies have specifically evaluated the effects of inadvertent ivermectin treatment during pregnancy (four case-control studies and one clinical trial). The results are presented in Table 2. The studies encompass a total of 839 women treated during pregnancy, including 442 women treated in the first trimester. No difference with controls is reported regarding pregnancy outcome, newborn health status or early child development. There is however no systematic database of inadvertent exposure during pregnancy to date. Based on these results, the proscription of ivermectin treatment during pregnancy was lifted for areas where women are at high risk of blindness. The decision to include pregnant women, however, is left at the discretion of the program directors [82].

Low ivermectin levels are found in human breast milk after a single oral dose of $150-250 \mathrm{mcg} / \mathrm{kg}$ in healthy women with a peak at $1 \mathrm{~h}$ post-ingestion of $18.5 \mathrm{ng} / \mathrm{ml}$ $[80,83]$. It remains detectable in human milk at very low levels $(<1 \mathrm{ng} / \mathrm{ml})$ for up to 14 days after a single dose [80]. Only nursing mothers in the 1st week after delivery are systematically excluded during MDA campaigns $[64,82]$.

A systematic review of the evidence regarding safety in pregnancy is needed. This is important because at population level the effectiveness of any ivermectin-based strategy will be determined by the population coverage achieved [84]. If the safety of the expected higher or more frequent doses needed for malaria is not established in pregnancy, excluding women in reproductive age is

Table 2 Five studies assessing the safety of ivermectin during pregnancy compared with community based controls

\begin{tabular}{|c|c|c|c|c|c|c|c|}
\hline Reference & Country & $\begin{array}{l}\text { Number of } \\
\text { pregnant } \\
\text { women }\end{array}$ & $\begin{array}{l}\text { Number } \\
\text { inadvertently } \\
\text { treated }\end{array}$ & $\begin{array}{l}\text { In the first } \\
\text { trimester }\end{array}$ & $\begin{array}{l}\text { Pregnancy } \\
\text { outcome }\end{array}$ & Child mortality & $\begin{array}{l}\text { Child develop- } \\
\text { ment }\end{array}$ \\
\hline Pacque et al. [81] & Liberia & 939 & 200 & $171(85 \%)$ & $\begin{array}{l}\text { No difference } \\
\text { with controls }\end{array}$ & $\begin{array}{l}\text { No difference } \\
\text { with controls }\end{array}$ & $\begin{array}{l}\text { No difference with } \\
\text { controls (follow- } \\
\text { up } 2 \text { years) }\end{array}$ \\
\hline $\begin{array}{l}\text { Doumbo et al. } \\
\text { [102] }\end{array}$ & Mali & 461 & 82 & Not stated & \multicolumn{2}{|c|}{ Data not readily assessable } & \\
\hline $\begin{array}{l}\text { Chippaux et al. } \\
\text { [103] }\end{array}$ & Cameroon & 511 & 110 & (93) $85 \%$ & $\begin{array}{l}\text { No difference } \\
\text { with controls }\end{array}$ & $\begin{array}{l}\text { No difference } \\
\text { with controls }\end{array}$ & $\begin{array}{l}\text { No difference with } \\
\text { controls (follow- } \\
\text { up } 1 \text { year) }\end{array}$ \\
\hline $\begin{array}{l}\text { Gyapong et al. } \\
\text { [104] }\end{array}$ & Ghana & 343 & 50 & (50) $100 \%$ & $\begin{array}{l}\text { No difference } \\
\text { with controls }\end{array}$ & $\begin{array}{l}\text { No difference } \\
\text { with controls }\end{array}$ & $\begin{array}{l}\text { No difference with } \\
\text { controls (follow- } \\
\text { up not stated) }\end{array}$ \\
\hline $\begin{array}{l}\text { Ndyomugyenyi } \\
\text { et al. [105] }\end{array}$ & Uganda & 834 & $397^{a}$ & $\begin{array}{l}\text { All in 2nd tri- } \\
\text { mester }\end{array}$ & $\begin{array}{l}\text { No difference } \\
\text { with controls }\end{array}$ & $\begin{array}{l}\text { No difference } \\
\text { with controls }\end{array}$ & Not included \\
\hline
\end{tabular}

a Clinical trial 
likely to reduce the efficacy of the intervention to reduce malaria transmission.

\section{Safety of ivermectin in infants and children}

Ivermectin is licensed for the treatment of children weighing more than $15 \mathrm{~kg}[7,8]$. In MDA campaigns a height of $90 \mathrm{~cm}$ is used as a proxy for $15 \mathrm{~kg}$. A preclinical toxicology study in 24 neonatal (7-13 days old) rhesus monkeys showed no adverse reaction after 2 weeks of daily doses of up to $100 \mathrm{mcg} / \mathrm{kg}$ [80]. An additional study in eight immature rhesus monkeys (13-21 months old), receiving doses of up to $1.200 \mathrm{mcg} / \mathrm{kg}$ for $14-16$ days showed no treatment related findings; three animals presented increased serum transaminases which was attributed to an infectious origin. In humans, there are only anecdotal case reports $[85,86]$ and small case series [87] of its use off-label in infants less than $15 \mathrm{~kg}$.

Similarly to pregnancy, the importance of a clear guidance regarding use in children weighing less than $15 \mathrm{~kg}$ is directly related to ivermectin MDA efficacy. At population level, coverage will be directly proportional to efficacy [84]. Importantly, the impact of including small children on the overall efficacy of ivermectin MDA for malaria will be related to the mosquito biting rate as well as risk of transmission in this particular population.

In areas of high transmission, where most of disease burden occurs in children under 5 years, this age group is expected to receive the largest proportional benefit of ivermectin MDA to reduce malaria transmission. In the context of the RIMDAMAL trial, the main outcome measure was malaria incidence in children under 5 years of age, where most of these children did not receive ivermectin [51]. Conducting dose-ranging studies in children will allow for increased population coverage of an ivermectin-based vector control intervention.

\section{Safety of ivermectin in high-risk groups}

There is no renal or hepatic ivermectin dose defined [7]. Renal dose adjustments would not appear necessary for a drug for which less than $1 \%$ is excreted unchanged in urine. It is conceivable that active metabolites exist that are eliminated renally. There is little information available on the safety of ivermectin in patients over 65 years of age. A report of excess deaths (several causes) among 47 residents of a nursing home following ivermectin MDA for scabies (single dose $150-200 \mathrm{mcg} / \mathrm{kg}$ ) [88] raised heated debate [89-92]. Ivermectin was licensed in Australia for the treatment of scabies in 2013 [93]. The elderly tend to have less adipose tissue and thus lower volumes of distribution for lipophilic drugs, such as ivermectin, which will result in higher plasma concentrations. They are also more prone to hypoalbuminaemia due to malnutrition, potentially yielding higher free concentrations of ivermectin. Lastly, hepatic function (and with that: capacity for detoxification) decreases with age.

There is no evident biological basis for concern on potential cardio-toxicity. Dukuly et al. [94] prospectively followed 32 men (mean age 61 years), including 20 with baseline EKG abnormalities and found no significant changes after ivermectin treatment.

HIV-infected individuals are not excluded from treatment based on their serological status [64]. Potential drug-drug interactions with anti retrovirals or TB drugs must be particularly taken into account when treating this special population (see drug interactions below).

Concerns about the theoretical risk of using ivermectin in patients with epilepsy have been resolved [82, 95].

\section{Environmental concerns about ivermectin}

There are three ways in which ivermectin can enter the environment: excretion from treated humans or animals, from disposal of pharmaceutical waste, or from emissions from manufacturing sites [80]. Haley et al. showed ivermectin undergoes rapid degradation in light and soil $[80,96]$. This, combined with tight binding to soil and sediment prevents environmental accumulation and minimizes its potential impact on non-target organisms $[80,96]$. Veterinary ivermectin formulations affect the dung fauna and there was initial concern that it may delay dung degradation [97]. More recent studies have suggest this is not the case [98].

\section{Key knowledge gaps regarding safety}

- The safety profile of ivermectin when used at higher doses, or with longer exposure treatment schemes.

- The safety of the proposed dose/schemes in populations likely to affect coverage if excluded i.e. potentially pregnant women and children under $15 \mathrm{~kg}$.

- New strategies to assess and prevent the Loa-related adverse effects.

- The safety of ivermectin in combination with anti-malarials and other drugs commonly used in endemic areas such as antiretrovirals, TB drugs and other antihelmintics.

\section{Conclusions}

Ivermectin MDA has the potential to reduce malaria transmission by increasing the mortality of malaria vectors biting treated individuals, particularly those only partially affected by LLINs and IRS due to behavioural or physiological resistance. A thorough understanding of the pharmacological properties of ivermectin is pivotal to design studies aiming at providing evidence for a policy recommendation.

Ivermectin is safe in MDA campaigns at the current dose approved for onchocerciasis and LF 150-200 mcg/ 
$\mathrm{kg}$ administered not more than four times a year. If used for malaria control, the dose and administration scheme will change. The efficacy of an ivermectin-based tool will be directly related to coverage; hence all population groups should be represented in the safety data collections, including women in reproductive age, children and the elderly. Additional preclinical safety studies might be needed to include these groups in clinical trials. The appropriate best time to include susceptible groups would be after the dose, formulation and administration scheme have been defined.

\section{Additional file}

Additional file 1. Studies assessing the efficacy of ivermectin to kill mosquitoes taking a loaded blood meal.

\begin{abstract}
Abbreviations
AUC: area under the curve; AE: adverse events; BBB: blood-brain-barrier; BCRP: breast cancer resistance protein; GABA: gamma-aminobutyric acid; $\mathrm{GluCl}$ : glutamate-gated chlorine channel; HIV: human immunodeficiency virus; INR: International Normalized Ratio; IRS: indoor residual spraying; $L_{50}$ : lethal concentration 50; LF: lymphatic filariasis; MDA: mass drug administration; NTDs: neglected tropical diseases; P-gp: p-glycoprotein; PK: pharmacokinetic; TB: tuberculosis; $V_{d}$ : volume of distribution.
\end{abstract}

\section{Authors' contributions}

CCh and RR prepared the first draft. All authors contributed to and reviewed the last version of the manuscript. All authors read and approved the final manuscript.

\section{Author details}

${ }^{1}$ ISGlobal, Barcelona Ctr. Int. Health Res. (CRESIB), Hospital Clínic-Universitat de Barcelona, Barcelona, Spain. ${ }^{2}$ Centro de Investigação em Saúde de Manhiça, Maputo, Mozambique. ${ }^{3}$ Instituto de Salud Tropical Universidad de Navarra, Pamplona, Spain. ${ }^{4}$ Division of Clinical Pharmacology \& Toxicology, University Hospital Basel, Basel, Switzerland. ${ }^{5}$ Harvard T.H. Chan School of Public Health, Boston, USA.

\section{Acknowledgements}

Carlos Chaccour is supported by a Ramón Areces fellowship. This work was partly supported by the PIUNA scheme from the University of Navarra. ISGlobal is a member of the CERCA Programme, Generalitat de Catalunya.

\section{Competing interests}

The authors declare that they have no competing interests.

\section{Declarations}

This publication is based on the background document prepared by the authors for the WHO Technical Consultation on "Preferred product characteristics of ivermectin for malaria transmission control", held in Geneva 30 March-1 April 2016. The main conclusions of this consultation were presented to the Malaria Policy Advisory Committee of WHO, and can be found at the Malaria Policy Advisory Committee website [99]. This manuscript solely represents the author's perspective after discussion with advisory groups and scientific collaborators.

\section{Publisher's Note}

Springer Nature remains neutral with regard to jurisdictional claims in published maps and institutional affiliations.

Received: 9 January 2017 Accepted: 6 April 2017

Published online: 24 April 2017
References

1. Bhatt S, Weiss DJ, Cameron E, Bisanzio D, Mappin B, Dalrymple U, et al. The effect of malaria control on Plasmodium falciparum in Africa between 2000 and 2015. Nature. 2015;526:207-11.

2. Durnez LC, Coosemans M. Residual transmission of malaria: an old issue for new approaches. In: Anopheles Mosquitoes-new insights into malaria vectors. Manguin S, editor. InTech; 2014.

3. Killeen GF. Characterizing, controlling and eliminating residual malaria transmission. Malar J. 2014;13:330.

4. Ranson $\mathrm{H}$, Lissenden $\mathrm{N}$. Insecticide resistance in African Anopheles mosquitoes: a worsening situation that needs urgent action to maintain malaria control. Trends Parasitol. 2016;32:187-96.

5. WHO. Global technical strategy for malaria 2016-2030. Geneva: World Health Organization. http://www.whoint/malaria/publications/ atoz/9789241564991/en/. Accessed Feb 2017.

6. Shoop WL, Mrozik H, Fisher MH. Structure and activity of avermectins and milbemycins in animal health. Vet Parasitol. 1995;59:139-56.

7. Merck \& Co. Stromectrol. FDA approved Package insert 2009. http:// www.accessdata.fda.gov/drugsatfda_docs/label/2009/050742s026lbl. pdf. Accessed Oct 2016.

8. Merck \& Co. Stromectrol. TGA-Australia approved Package insert 2014. https://www.ebs.tga.gov.au/ebs/picmi/picmirepository.nsf/ pdf?OpenAgent\&id=CP-2011-PI-02659-3\&d=2016071016114622483. Accessed Feb 2017

9. Chaccour CJ, Kobylinski KC, Bassat Q, Bousema T, Drakeley C, Alonso P, et al. Ivermectin to reduce malaria transmission: a research agenda for a promising new tool for elimination. Malar J. 2013;12:153.

10. Foy BD, Kobylinski KC, da Silva IM, Rasgon JL, Sylla M. Endectocides for malaria control. Trends Parasitol. 2011:27:423-8.

11. Meyers Jl, Gray M, Kuklinski W, Johnson LB, Snow CD, Black WC, et al. Characterization of the target of ivermectin, the glutamate-gated chloride channel, from Anopheles gambiae. J Exp Biol. 2015;218:1478-86.

12. Menez C, Sutra JF, Prichard R, Lespine A. Relative neurotoxicity of ivermectin and moxidectin in Mdr1ab (-/-) mice and effects on mammalian GABA(A) channel activity. PLoS Negl Trop Dis. 2012;6:e1883.

13. Fritz ML, Siegert PY, Walker ED, Bayoh MN, Vulule JR, Miller JR. Toxicity of bloodmeals from ivermectin-treated cattle to Anopheles gambiae s.l. Ann Trop Med Parasitol. 2009:103:539-47.

14. Gardner K, Meisch MV, Meek CL, Biven WS. Effects of ivermectin in canine blood on Anopheles quadrimaculatus, Aedes albopictus and Culex salinarius. J Am Mosq Control Assoc. 1993;9:400-2.

15. Edwards G, Dingsdale A, Helsby N, Orme ML, Breckenridge AM. The relative systemic availability of ivermectin after administration as capsule, tablet, and oral solution. Eur J Clin Pharmacol. 1988;35:681-4.

16. Gonzalez Canga A, Sahagun Prieto AM, Diez Liebana MJ, Fernandez Martinez N, Sierra Vega M, Garcia Vieitez JJ. The pharmacokinetics and interactions of ivermectin in humans-a mini-review. AAPS J. 2008;10:42-6.

17. Chiodini PL, Reid AJ, Wiselka MJ, Firmin R, Foweraker J. Parenteral ivermectin in Strongyloides hyperinfection. Lancet. 2000;355:43-4.

18. Marty FM, Lowry CM, Rodriguez M, Milner DA, Pieciak WS, Sinha A, et al. Treatment of human disseminated strongyloidiasis with a parenteral veterinary formulation of ivermectin. Clin Infect Dis. 2005;41:e5-8.

19. Homeida MM, Malcolm SB, ElTayeb AZ, Eversole RR, Elassad AS, Geary TG, et al. The lack of influence of food and local alcoholic brew on the blood level of Mectizan((R)) (ivermectin). Acta Trop. 2013;127:97-100.

20. Miyajima A, Hirota T, Sugioka A, Fukuzawa M, Sekine M, Yamamoto $Y$, et al. Effect of high-fat meal intake on the pharmacokinetic profile of ivermectin in Japanese patients with scabies. J Dermatol. 2016:43:1030-6.

21. Preissner S, Kroll K, Dunkel M, Senger C, Goldsobel G, Kuzman D, et al. SuperCYP: a comprehensive database on Cytochrome P450 enzymes including a tool for analysis of CYP-drug interactions. Nucleic Acids Res. 2010;38:D237-43.

22. Schinkel AH, Wagenaar E, van Deemter L, Mol CA, Borst P. Absence of the mdr1a P-Glycoprotein in mice affects tissue distribution and pharmacokinetics of dexamethasone, digoxin, and cyclosporin A. J Clin Invest. 1995;96:1698-705.

23. Vanapalli SR, Chen Y, Ellingrod VL, Kitzman D, Lee Y, Hohl RJ, et al. Orange juice decreases the oral bioavailability of ivermectin in healthy volunteers. Clin Pharmacol Ther. 2003;73:P94. 
24. Dowling P. Pharmacogenetics: it's not just about ivermectin in collies. Can Vet J. 2006:47:1165-8.

25. Schinkel AH, Smit JJ, van Tellingen O, Beijnen JH, Wagenaar E, van Deemter $L$, et al. Disruption of the mouse mdr1 a P-glycoprotein gene leads to a deficiency in the blood-brain barrier and to increased sensitivity to drugs. Cell. 1994;77:491-502.

26. Jani M, Makai I, Kis E, Szabo P, Nagy T, Krajcsi P, et al. Ivermectin interacts with human ABCG2. J Pharm Sci. 2011;100:94-7.

27. Chiu SH, Lu AY. Metabolism and Tissue Residues. In: Campbell WC, editor. Ivermectin and abamectin. New York: Springer; 1989. p. 131-43.

28. Elkassaby $\mathrm{MH}$. Ivermectin uptake and distribution in the plasma and tissue of Sudanese and Mexican patients infected with Onchocerca volvulus. Trop Med Parasitol. 1991;42:79-81.

29. Baraka OZ, Mahmoud BM, Marschke CK, Geary TG, Homeida MM, Williams JF. Ivermectin distribution in the plasma and tissues of patients infected with Onchocerca volvulus. Eur J Clin Pharmacol. 1996;50:407-10.

30. Lam J, Baello S, Iqbal M, Kelly LE, Shannon PT, Chitayat D, et al. The ontogeny of P-glycoprotein in the developing human blood-brain barrier: implication for opioid toxicity in neonates. Pediatr Res. 2015;78:417-21.

31. Lankas GR, Minsker DH, Robertson RT. Effects of ivermectin on reproduction and neonatal toxicity in rats. Food Chem Toxicol. 1989;27:523-9.

32. Zeng Z, Andrew NW, Arison BH, Luffer-Atlas D, Wang RW. Identification of cytochrome P4503A4 as the major enzyme responsible for the metabolism of ivermectin by human liver microsomes. Xenobiotica. 1998;28:313-21.

33. Treluyer JM, Cheron G, Sonnier M, Cresteil T. Cytochrome P-450 expression in sudden infant death syndrome. Biochem Pharmacol. 1996:52:497-504

34. Treluyer JM, Gueret G, Cheron G, Sonnier M, Cresteil T. Developmental expression of CYP2C and CYP2C-dependent activities in the human liver: in vivo/in vitro correlation and inducibility. Pharmacogenetics. 1997;7:441-52.

35. Chiu SH, Taub R, Sestokas E, Lu AY, Jacob TA. Comparative in vivo and in vitro metabolism of ivermectin in steers, sheep, swine, and rat. Drug Metab Rev. 1987;18:289-302.

36. Fink DW, Porras AG. Pharmacokinetics of ivermectin in animals and humans. In: Campbell WC, editor. Ivermectin and abamectin. New York: Springer; 1989. p. 113-30.

37. Kobylinski K, Davidson S, Jittamala P, Pukrittayakamee S, Hanboonkunupakarn B, van der Pluijm R, et al. Mosquito-lethal efficacy of ivermectin, dihydroartemisinin-piperaquine, and primaquine: Ivermectin for Malaria in Southeast Asia (IMSEA Study). Oral presentation during the 65th Annual Meeting of the ASTMH Atlanta 2016. 2016

38. Smit M, Ochomo E, ter Kuile F. Efficacy and safety of high-dose ivermectin for reducing malaria transmission: A dose finding study (IVERMAL). Oral presentation during the 65th Annual Meeting of the ASTMH Atlanta 2016.

39. Lespine A, Menez C, Bourguinat C, Prichard RK. P-glycoproteins and other multidrug resistance transporters in the pharmacology of anthelmintics: prospects for reversing transport-dependent anthelmintic resistance. Int J Parasitol Drugs Drug Resist. 2012;2:58-75.

40. Alvinerie M, Dupuy J, Kiki-Mvouaka S, Sutra JF, Lespine A. Ketoconazole increases the plasma levels of ivermectin in sheep. Vet Parasitol. 2008;157:117-22.

41. Hugnet C, Lespine A, Alvinerie M. Multiple oral dosing of ketoconazole increases dog exposure to ivermectin. J Pharm Pharm Sci. 2007:10:311-8.

42. Ouedraogo AL, Bastiaens GJ, Tiono AB, Guelbeogo WM, Kobylinski KC, Ouedraogo A, et al. Efficacy and safety of the mosquitocidal drug ivermectin to prevent malaria transmission after treatment: a double-blind, randomized, clinical trial. Clin Infect Dis. 2015;60:357-65.

43. Smit MR, Ochomo E, Aljayyoussi G, Kwambai T, Abong'o B, Bayoh N, et al. Efficacy and safety of high-dose ivermectin for reducing malaria transmission (IVERMAL): protocol for a double-blind, randomized, placebo-controlled, dose-finding trial in Western Kenya. JMIR Res Protoc. 2016;5:e213.

44. Chaccour CJ, Rabinovich NR, Slater H, Canavati SE, Bousema T, Lacerda M, et al. Establishment of the ivermectin research for malaria elimination network: updating the research agenda. Malar J. 2015;14:243.

45. Kobylinski KC, Deus KM, Butters MP, Hongyu T, Gray M, da Silva IM, et al. The effect of oral anthelmintics on the survivorship and re-feeding frequency of anthropophilic mosquito disease vectors. Acta Trop. 2010;116:119-26.

46. Kobylinski KC, Foy BD, Richardson JH. Ivermectin inhibits the sporogony of Plasmodium falciparum in Anopheles gambiae. Malar J. 2012;11:381.

47. Sylla M, Kobylinski KC, Gray M, Chapman PL, Sarr MD, Rasgon JL, et al. Mass drug administration of ivermectin in south-eastern Senegal reduces the survivorship of wild-caught, blood fed malaria vectors. Malar J. 2010;9:365.

48. Seaman JA, Alout H, Meyers Jl, Stenglein MD, Dabire RK, LozanoFuentes $S$, et al. Age and prior blood feeding of Anopheles gambiae influences their susceptibility and gene expression patterns to ivermectin-containing blood meals. BMC Genom. 2015;16:797.

49. Slater H, Kobylinski KC, Foy B, Alout H, Churcher T, Bousema T, Ghani A. Ivermectin for malaria control: model validation to existing data and designing trials to detect an impact using clinical and entomological metrics. In 64th Annual meeting of the American Society of Tropical Medicine and Hygiene; 2015 Oct 25-29; Philadelphia.

50. Slater HC, Walker PG, Bousema T, Okell LC, Ghani AC. The potential impact of adding ivermectin to a mass treatment intervention to reduce malaria transmission: a modelling study. J Infect Dis. 2014;210:1972-80.

51. Foy BD, Alout H, Seaman JA, Coulidiaty AGV, Bougma R, Rouamba N, et al. Update on Repeat Ivermectin Mass Drug Administrations for control of MALaria (RIMDAMAL): a randomized pilot safety and efficacy study (poster). In: 64th annual meeting of the American Society of Tropical Medicine and Hygiene 2015 Philadelphia, USA.

52. Bellinger AM, Jafari M, Grant TM, Zhang S, Slater HC, Wenger EA, et al. Oral, ultra-long-lasting drug delivery: application toward malaria elimination goals. Sci Transl Med. 2016:8:365ra157.

53. Chaccour C, Barrio A, Gil Royo AG, Martinez Urbistondo D, Slater H, Hammann $F$, et al. Screening for an ivermectin slow-release formulation suitable for malaria vector control. Malar J. 2015;14:102.

54. International Transporter C, Giacomini KM, Huang SM, Tweedie DJ, Benet LZ, Brouwer KL, et al. Membrane transporters in drug development. Nat Rev Drug Discov. 2010;9:215-36.

55. Butters MP, Kobylinski KC, Deus KM, da Silva IM, Gray M, Sylla M, et al. Comparative evaluation of systemic drugs for their effects against Anopheles gambiae. Acta Trop. 2012;121:34-43.

56. Kobylinski K, Ubalee R, Ponlawat A, McCardle W, Foy B, Szumlas D, et al. Ivermectin inhibits the development of Plasmodium vivax in Anopheles dirus. 64th Annual meeting of the American Society of Tropical Medicine and Hygiene; 2015 Oct 25-29; Philadelphia USA.

57. da Cruz FP, Martin C, Buchholz K, Lafuente-Monasterio MJ, Rodrigues T, Sonnichsen B, et al. Drug screen targeted at Plasmodium liver stages identifies a potent multistage antimalarial drug. J Infect Dis. 2012;205:1278-86.

58. Pinilla Y, Lopes S, Fabri C, Sampaio V, Melo G, Lacerda M, et al. Effect of ivermectin on Plasmodium vivax in its interaction with Anopheles aquasalis (poster). 65th Annual meeting of the American Society of Tropical Medicine and Hygiene; 2016 Nov 11-17; Atlanta, USA.

59. Mectizan Donation Program. Annual highlights 2015. http://www. mectizan.org/sites/www.mectizan.org/files/attachments/resources/ MDP_AnnHigh2015_Design\%20041516FINAL2\%20\%281\%29.pdf. Accessed Aug 2016.

60. Burrows JN, van Huijsduijnen RH, Mohrle JJ, Oeuvray C, Wells TN. Designing the next generation of medicines for malaria control and eradication. Malar J. 2013;12:187.

61. Golan DT, AH; Armstrong, EJ; Armstrong, AW. Principles of pharmacology: the pathophysiologic basis of drug therapy, 3rd Ed. Philadelphia. USA: LWW; 2011

62. Guzzo CA, Furtek Cl, Porras AG, Chen C, Tipping R, Clineschmidt $\mathrm{CM}$, et al. Safety, tolerability, and pharmacokinetics of escalating high doses of ivermectin in healthy adult subjects. J Clin Pharmacol. 2002:42:1122-33.

63. Centers for disease control and prevention (CDC). Prescription medication for the treatment of scabies. http://www.cdc.gov/parasites/scabies/health_professionals/meds.html. Accessed June 2016. 
64. WHO. Preventive chemotherapy in human helminthiasis. Coordinated use of anthelminthic drugs in control interventions. A manual for health professionals and programme managers. http://apps.who.int/ iris/bitstream/10665/43545/1/9241547103_eng.pdf. Accessed Aug 2016.

65. APOC. Conceptual and operational framework of onchocerciasis elimination with ivermectin treatment. 2010. http://www.whoint/apoc/ oncho_elimination_report_englishpdf. Accessed Aug 2015.

66. Mackenzie CD, Geary TG, Gerlach JA. Possible pathogenic pathways in the adverse clinical events seen following ivermectin administration to onchocerciasis patients. Filaria J. 2003;2(Suppl 1):S5.

67. Kamgno J, Gardon J, Gardon-Wendel N, Demanga N, Duke BO, Boussinesq M. Adverse systemic reactions to treatment of onchocerciasis with ivermectin at normal and high doses given annually or three-monthly. Trans R Soc Trop Med Hyg. 2004;98:496-504.

68. Njoo FL, Beek WM, Keukens HJ, van Wilgenburg H, Oosting J, Stilma JS, et al. Ivermectin detection in serum of onchocerciasis patients: relationship to adverse reactions. Am J Trop Med Hyg. 1995;52:94-7.

69. Ejere HO, Schwartz E, Wormald R, Evans JR. Ivermectin for onchocercal eye disease (river blindness). Cochrane Database Syst Rev. 2012;8:CD002219.

70. Gardon J, Gardon-Wendel N, Demanga N, Kamgno J, Chippaux JP, Boussinesq M. Serious reactions after mass treatment of onchocerciasis with ivermectin in an area endemic for Loa loa infection. Lancet. 1997;350:18-22

71. Edwards G. Ivermectin: does P-glycoprotein play a role in neurotoxicity? Filaria J. 2003;2(Suppl 1):S8.

72. The Mectizan Expert Committee and The Technical Consultative Committee. Recommendations for the treatment of Onchocerciasis with Mectizan in areas co-endemic for Onchocerciasis and Loiasis. http:// www.who.int/apoc/publications/englishmectccloarecs-june04.pdf. Accessed July 2016.

73. Zoure HG, Wanji S, Noma M, Amazigo UV, Diggle PJ, Tekle AH, et al. The geographic distribution of Loa loa in Africa: results of large-scale implementation of the Rapid Assessment Procedure for Loiasis (RAPLOA). PLoS Negl Trop Dis. 2011;5:e1210.

74. D'Ambrosio MV, Bakalar M, Bennuru S, Reber C, Skandarajah A, Nilsson $L$, et al. Point-of-care quantification of blood-borne filarial parasites with a mobile phone microscope. Sci Transl Med. 2015;7:286re4.

75. Drame PM, Meng Z, Bennuru S, Herrick JA, Veenstra TD, Nutman TB. Identification and validation of Loa loa microfilaria-specific biomarkers: a rational design approach using proteomics and novel immunoassays. MBio. 2016;7:e02132.

76. Thomsen EK, Sanuku N, Baea M, Satofan S, Maki E, Lombore B, et al. Efficacy, safety, and pharmacokinetics of coadministered diethylcarbamazine, albendazole, and ivermectin for treatment of Bancroftian filariasis. Clin Infect Dis. 2016;62:334-41.

77. Ministere des affaires sociales de la sante et des droits des femmes. STROMECTOL 3 mg, comprimé-Résumé des caractéristiques du produit. http://base-donnees-publique.medicaments.gouv.fr/extrait. php? specid=61350360. Accessed Aug 2016.

78. MedicineWise N. Ivermectin (Stromectol) for typical and crusted scabies. 2014. Radar, https://www.npsorgau/radar/articles/ivermectinstromectol-for-typical-and-crusted-scabies. Accessed Aug 2016.

79. RIMDAMAL. Study information available at Clinicaltrials.org. https:// clinicaltrials.gov/ct2/show/NCT02509481?term=rimdamal\&rank=1. Accessed Aug 2015.

80. FDA. Center for drug evaluation and research. Approval package for Mectizan. http://www.accessdata.fda.gov/drugsatfda_docs/ nda/96/050742ap.pdf. Accessed July 2016.

81. Pacque M, Munoz B, Poetschke G, Foose J, Greene BM, Taylor HR. Pregnancy outcome after inadvertent ivermectin treatment during community-based distribution. Lancet. 1990;336:1486-9.

82. Brown KR. Changes in the use profile of Mectizan: 1987-1997. Ann Trop Med Parasitol. 1998;92(Suppl 1):S61-4.
83. Ogbuokiri JE, Ozumba BC, Okonkwo PO. Ivermectin levels in human breastmilk. Eur J Clin Pharmacol. 1993;45:389-90.

84. Chaccour C, Rabinovich NR. Ivermectin to reduce malaria transmission II. Considerations regarding clinical development pathway. Malaria J (submitted)

85. Chaccour CJ, Del Pozo JL. Case 23-2012: a man with abdominal pain and weight loss. N Engl J Med. 2012;367:1670-1.

86. Roberts LJ, Huffam SE, Walton SF, Currie BJ. Crusted scabies: clinical and immunological findings in seventy-eight patients and a review of the literature. J Infect. 2005;50:375-81.

87. Becourt C, Marguet C, Balquerie X, Joly P. Treatment of scabies with oral ivermectin in 15 infants: a retrospective study on tolerance and efficacy. Br J Dermatol. 2013;169:931-3.

88. Barkwell R, Shields S. Deaths associated with ivermectin treatment of scabies. Lancet. 1997;349:1144-5.

89. Bredal WP. Deaths associated with ivermectin for scabies. Lancet. 1997;350:216.

90. Coyne PE, Addiss DG. Deaths associated with ivermectin for scabies. Lancet. 1997;350:215-6 (author reply 16).

91. Currie B, Huffam S, O'Brien D, Walton S. Ivermectin for scabies. Lancet. 1997;350:1551.

92. Reintjes R, Hoek C. Deaths associated with ivermectin for scabies. Lancet. 1997;350:215 (author reply 16)

93. Australian Government: Department of health. Therapeutic goods administration. Australian Public Assessment Report for Ivermectin. 2013. https://www.tga.gov.au/sites/default/files/auspar-ivermectin-131030.docx. Accessed Aug 2016.

94. Dukuly ZD, Pacque M, Nara A, Taylor HR, Williams PN, Greene BM. A prospective study in high risk subjects of electrocardiographic changes with ivermectin. Trop Med Parasitol. 1990;41:73-4.

95. Kipp W, Burnham G, Kamugisha J. Improvement in seizures after ivermectin. Lancet. 1992;340:789-90.

96. Halley BA, VandenHeuvel WJ, Wislocki PG. Environmental effects of the usage of avermectins in livestock. Vet Parasitol. 1993;48:109-25.

97. Wall R, Strong L. Environmental consequences of treating cattle with the antiparasitic drug ivermectin. Nature. 1987;327:418-21.

98. Barth D, Heinze-Mutz EM, LangholffW, Roncalli RA, Schluter D. Colonisation and degradation of dung pats after subcutaneous treatment of cattle with ivermectin or levamisole. Appl Parasitol. 1994;35:277-93.

99. MPAC meeting, 14-16 September 2016: Update on a proposed Ivermectin target product profile. http://www.whoint/entity/malaria/ $\mathrm{mpac} / \mathrm{mpac}$-sept2016-invermectin-session9pdf?ua=1. Accessed March 2017.

100. Awadzi K, Opoku NO, Addy ET, Quartey BT. The chemotherapy of onchocerciasis. XIX: the clinical and laboratory tolerance of high dose ivermectin. Trop Med Parasitol. 1995;46:131-7.

101. Awadzi K, Attah SK, Addy ET, Opoku NO, Quartey BT. The effects of highdose ivermectin regimens on Onchocerca volvulus in onchocerciasis patients. Trans R Soc Trop Med Hyg. 1999;93:189-94.

102. Doumbo O, Soula G, Kodio B, Perrenoud M. Ivermectin and pregnancy in mass treatment in Mali (in French). Bull Soc Pathol Exot. 1992;85:247-51.

103. Chippaux JP, Gardon-Wendel N, Gardon J, Ernould JC. Absence of any adverse effect of inadvertent ivermectin treatment during pregnancy. Trans R Soc Trop Med Hyg. 1993:87:318.

104. Gyapong JO, Chinbuah MA, Gyapong M. Inadvertent exposure of pregnant women to ivermectin and albendazole during mass drug administration for lymphatic filariasis. Trop Med Int Health. 2003;8:1093-101.

105. Ndyomugyenyi R, Kabatereine N, Olsen A, Magnussen P. Efficacy of ivermectin and albendazole alone and in combination for treatment of soil-transmitted helminths in pregnancy and adverse events: a randomized open label controlled intervention trial in Masindi district, western Uganda. Am J Trop Med Hyg. 2008;79:856-63. 